\title{
Behavioral, Emotional, and Academic Adjustment in a National Probability Sample of African American Children: Effects of Age, Gender, and Family Structure
}

\author{
Oscar A. Barbarin \\ Robin E. Soler \\ University of Michigan
}

\begin{abstract}
The prevalence of developmental and psychological disturbances among African American children often is estimated from studies of the general population. In contrast, this study presents information obtained from a nonclinical sample of 1,458 African American parents on the academic, behavioral, and socioemotional adjustment of their children. Symptoms comprising an agitation syndrome (restlessness, anxiety, and poor concentration) were most frequently reported. Irrespective of age, boys were more likely than girls to exhibit adjustment difficulties. However, boys aged 5 to 11 were at greatest risk for socioemotional problems. Children living in single-adult households were less well adjusted than children living with both biological parents, but this effect depended on the child's age. Although family structure was related to adjustment of young children, it made no difference for adolescents. Moreover, with the exception of mothergrandmother combinations, the beneficial effect of living in a two-adult household did not obtain for family structures that do not include both biological parents. The agitation syndrome attributed to living in a chronically stressful environment could be easily mistaken for and be the reason why African American boys are so frequently diagnosed with attention deficit hyperactivity disorder (ADHD).
\end{abstract}

Barring anomalies of nature, physical maturation in young children is accompanied by parallel development in other domains resulting in increased organization of behavior, affect, and cognitive functioning. Accordingly, children acquire, over time, the capacity to direct their own behavior, inhibit action, focus attention, regulate emotional arousal, and maintain social relations in accord with and in response to the demands of their social JOURNAL OF BLACK PSYCHOLOGY, Vol. 19 No. 4, November 1993 423-446 CC 1993 The Association of Black Psychologists 
environment (Maccoby, 1980). These developing competencies are the foundation of children's socioemotional and academic adjustment. Their emergence is widely considered to be ontogenetic and universal. Research on emotional adjustment of children suggests that the overwhelming majority of children develop into socially competent and emotionally adjusted adults. Accordingly, rates of serious psychological disturbance are relatively low. In a study of a representative sample of school-age children, the problems reported most frequently were overanxious disorder (9.9\%), $\mathrm{ADHD}(6.2 \%)$, and conduct disorder (5.5.\%) (Offord, Boyle, \& Racine, 1989). Oppositional disorders were also common (5.7\% to $9.9 \%$ ). Less common were problems of mood, such as depression and dysthymia (1.8\% to $5.9 \%)$.

However, research on high-risk populations has provided reason to question assumptions of universality of social development and whether low rates of disturbance occur across all segments of the population. A number of life circumstances can cause children to veer off the expected developmental course. For example, poor nutrition, in-utero exposure to drugs such as cocaine or alcohol, radiation, toxins, or Rubella, premature birth, birth injuries, and anoxia have immediate adverse effects on the developing fetus or infant-effects that have long-term consequences for physical, cognitive, and socioemotional development in later life (Willis \& Walker, 1989). Similarly, for children traumatized by family instability, chronic illness, death of a parent, domestic violence, or sexual abuse, social development might not follow the typical progression. Research on such traumatized groups show that a remarkable number of children are resilient in the face of these severe challenges (Masten, 1989). Nevertheless, familial and environmental factors could influence the styles of emotional regulation they adapt, the level of social functioning they attain, and the types of problem-solving competencies they acquire.

Epidemiological research has shown that the probability of experiencing difficulties in emotional functioning also differs considerably by age, gender, social class, and family structure. Girls exhibited more difficulties related to anxiety and depressive disorders than did boys, and this gender discrepancy increased with age (Costello, 1989). Males and children from low SES families were more likely to exhibit problems of conduct, and older children had more difficulties in this domain than did younger children (Costello, 1989). In addition, children from single-adult households were more likely to exhibit behavior problems than were those from two-parent households. However, the relationship between family structure and SES are so often confounded that the unique contribution of family structure to behavioral disorders is unclear. 
Until just recently, the role of sociocultural factors in emotional development has largely been neglected by developmental researchers, leaving the impression that it is largely independent of life situation, ethnicity, and culture. By virtue of life circumstances driven by poverty and racism (e.g., prenatal insults, family instability, parental economic distress, divorce, exposure to violence, etc.), African American children are high on the list of at-risk populations. Because epidemiological data on rates of disturbances often are not disaggregated by ethnicity, we are unable to specify the nature of the problems most often affecting African American children. Modest support for the separate pursuit of such data on specific ethnic groups comes from a somewhat unlikely source: discrepant estimates of disorders reported across national boundaries. Studies separately assessing the frequencies of serious psychopathology in mainland U.S., Canadian, Puerto Rican, and New Zealander children report overall rates of disturbance ranging from $17 \%$ to $22 \%$ (Costello, 1989). Meaningful differences are noted when the rates for specific disorders are examined. For example, among Puerto Rican children, 9.9\% were found to have attention deficit hyperactivity disorder (ADHD). These rates were $30 \%$ to $500 \%$ higher than those observed in children in Canada, the mainland United States, and New Zealand. Rates of depression for the Puerto Rican children (5.9\%) were 300\% higher than for children from the other countries. The Canadian sample had rates of overanxious disorder that were about two to three times as high as they were for the U.S., Puerto Rican, and New Zealand samples. The meaning of these differences are difficult to interpret. Frequently, they are dismissed as aberrations due to design and measurement error. But ethnic and cultural explanations cannot be ruled out. Culture as reflected in lifestyles, values, and parental and peer socialization practices might play a determining role in shaping the nature of adjustment difficulties and competencies that children develop. These differences might also be interpreted as responses to imperatives of culture and social environment described by Ogbu (1988).

\section{STATEMENT OF THE PROBLEM}

Epidemiological studies of children's emotional and behavioral adjustment provide credible estimates of the rates of serious disorders in the general population of children. However, it is difficult to judge the accuracy of these data in characterizing the emotional adjustment of African American children, who are more likely to experience economic hardship, homelessness, and live under conditions of poverty for extended periods of time. The 
resulting combination of physical risks, social challenges, and environmental hazards pose a significant challenge to and threaten the well-being of African American children. Therefore, it is unclear whether existing estimates adequately account for the life situation of many African American children.

The major purpose of this study was to present the frequency of behavioral, emotional, and academic adjustment problems in a national sample of African American children and adolescents. In addition, we examined patterns of adjustment within specific groups based on age, gender, socioeconomic status (SES), and family structure. In this way we can identify groups which are at higher risk of maladjustment. This work can serve as a point of departure for future research on the mechanisms or processes that place specific age, gender, SES, or family structure groups at increased risk of impaired social development. Through an identification of the most frequently occurring problems and the most vulnerable groups, better decisions can be made about prioritizing allocation of resources to the most prevalent conditions. The extent of our knowledge of the psychological status and functioning of children is rather extensive and conclusive with respect to age, gender, and SES but preliminary and rudimentary with respect to family structure. We expect that age and gender will have the same effect among African American children that has been observed in other groups.

\section{METHOD}

\section{PROCEDURE}

The analyses reported here are based on data gathered in the 1981 National Health Interview Survey-Child Health Supplement (NHIS-CHS) under the auspices of the U.S. Department of Health and Human Services, National Center for Health Statistics. The basic purpose of the NHIS was to gather information about the prevalence of physical, developmental, and psychological conditions that would reflect the health service needs of a representative sample of the nation's adults and children. These data were intended for use in planning for deployment of the nation's health care resources and as a guide in formulating national health policy.

To gather information about the child, face-to-face interviews were conducted by trained staff in the home of informants who were either parents or primary guardians of the randomly selected target child. The Child Health Supplement specifically focuses on the child's general health status, school 
development, learning behavior, and use of health services. In addition to asking questions about the child's development, education, health, and symptoms of affective and behavioral disorders, information was gathered on household composition, demographic status of biological mother, father, and primary caretaker, and data specific to pregnancy, birth, and child care.

\section{SAMPLE}

The universe used for the sampling frame was the civilian, noninstitutionalized population of the 50 states and the District of Columbia. The sampling methodology involved a multistage probability sample from 1,924 geographically defined primary sampling units. The resulting sample is, by intent, a representative sample of the population of the United States with a large national probability sample of African American children. The children in the sample ranged in age from 0 to 17 years of age. The sample used in this study consisted of all African American parents or caretakers of children, aged 4-17, and 1,458 children, with an almost equal number of males and females. Table 1 presents descriptive information and demographic details on this sample.

\section{MEASURES}

\section{Child Adjustment}

Behavior and affective adjustment were assessed using 32 brief symptom items assembled by a panel of developmental consultants. Items relating to child adjustment were selected to cover the domains included in the Child Behavior Checklist (CBCL; Achenbach \& Edelbrock, 1983), a widely used measure of child functioning. Items selected had the highest test-retest reliabilities and loadings on the CBCL subscales (Peterson \& Zill, 1986). Of the 32 items, 23 were administered to all, 4 items to adolescents (aged 12 and older) only, and another 5 to children (aged 11 and younger) only. These items were not presented when the target child was under 5 years of age. Interviewers presented the questions on a card, read them to the parents, and recorded the responses in the interview schedule. For each item, parents indicated whether it was often true, sometimes true, or not true of the target child. In the scoring, "sometimes true" and "often true" were coded as 1 and "not true" as $\mathbf{0}$. Scores were summed to yield the total Problems Behavior Index score and the subscale scores. 
TABLE 1

Sample Characteristics $(N=1,458)$

\begin{tabular}{lcc}
\hline \hline Variable & $\mathrm{n}$ & $\%$ \\
\hline Age (in years) & & \\
$5-7$ & 384 & 26.3 \\
$7-9$ & 396 & 27.2 \\
$10-12$ & 310 & 21.3 \\
$13-17$ & 368 & 25.2 \\
Family structure & & \\
$\quad$ Biological mother & 405 & 27.8 \\
Other single parent & 61 & 4.2 \\
Two biological parents & 368 & 25.2 \\
Two parent-extended & 206 & 14.1 \\
Three generation & 125 & 8.6 \\
Income & & \\
Under \$4.9K & 274 & 18.8 \\
\$5K to \$9.9K & 286 & 19.6 \\
\$10K to \$24.9K & 480 & 32.9 \\
\$25K and above & 238 & 16.3 \\
Gender & & \\
Male & 734 & 50.3 \\
Female & 724 & 49.7 \\
\hline
\end{tabular}

Subscales were developed on the basis of principal components analysis of all items. Separate analyses were performed for children and adolescents in the sample. The factor analyses yielded five similar factors for the two age groups: Antisocial, Anxious/Depressed, Headstrong, Hyperactive, and Peer Conflict/Social Withdrawal. In addition, a sixth factor, Immature/Dependency, was found for the children. The estimate of internal consistency (Cronbach's alpha) averaged .69 for the subscales. The Problem Behavior Index had a reliability estimate of .90 .

Antisocial assesses the occurrence of symptoms related to socially disapproved, aggressive and delinquent type behavior. The scale consists of six items addressing lying, cheating, bullying and being mean, disobeying at school, lacking remorse for misbehavior, and not getting along with teachers. For young children, there is an item related to being destructive, and for adolescents, an item relating to hanging out with troublemakers.

Anxiety/Depression assesses a set of symptoms generally grouped under the rubric of internalizing disorders. These are generally mood disturbances related to sad affect and agitation. This scale contains five items tapping mood changes, feeling unloved, fear, worthlessness, and sadness. For adolescents only, there is a sixth item referring to excessive worry. 
Headstrong assesses a trait or disposition that is best characterized as oppositional. Scores indicate the extent to which a child or adolescent is noncompliant and difficult to influence, particularly with respect to altering or redirecting behavior. It contains five items addressing stubbornness, strong temper, disobedience at home, arguing, and being high-strung.

Hyperactivity includes a constellation of behaviors often associated with attention deficit disorder. It refers to a heightened level of activity, an inability to inhibit movement, and is often associated with difficulties in concentration and focusing attention. The scale contains five items pertaining to inability to concentrate, being easily confused, and being impulsive, obsessive, and restless.

Peer Conflict/Social Withdrawal assesses problems in social functioning. This three-item scale assesses difficulty in getting along with and being liked by other children and being withdrawn.

Immaturity/Dependence refers to an excessive reliance on others, particularly adults, and is suggestive of a lack of independence and self assurance. It is characterized by a lack of independence and autonomy.

The Problem Behavior Index Score is a sum of all 28 items (27 for adolescents) representing the total prevalence of problems. The range of scores is 0 to 28 , with a mean score of $6.44(S D=5.7)$ for the NHIS-CHS normative sample of 11,588 children and adolescents.

In addition, academic adjustment assesses the quality of performance and achievement in school settings. Parents indicated whether the target child repeated a grade and experienced suspension or expulsion, ranked the student (5-point rating from the top to the bottom of the class), and rated the quality of overall performance $(1=$ doing really well, $2=$ about as well as he/she can, 3 = could be doing better).

\section{Family Structure}

Because of the ambiguous ways in which family structure has been defined, a five-part category reflecting the complexity and heterogeneity of family structures among African American families was developed. All people reported living in a household were included in these five categories.

Biological Mother Only includes households where the only adult recorded as present is the biological mother of the target child.

Single Other is a family structure in which a single adult other than the biological mother resides with the target child. This person can be a biological father or adoptive, step-, or foster father, brother, uncle or cousin, mother, sister, aunt, or unrelated caretaker. This adult is over the age of 18 and is not considered a grandparent by the respondent. 
Biological Mother and Father refers to the traditional two-parent nuclear family in which two adults, the biological mother and the biological father, reside with the target child.

Two-Parent Other includes any combination of adults in the household where one parent may be a biological parent of the target child. This category includes step-, foster, and adopted families, parent/adult sibling families, and two-generation extended kin and nonkin families. This category does not include two-parent three-generation (grandparent present) families.

Three-Generation Households are those that have at least one grandparent present.

\section{RESULTS}

\section{DISTRIBUTION OF PROBLEMS}

The data analysis began with an examination of the frequencies of reported problems disaggregated by gender and by age (4-11 and 12-17) and then examined symptoms by family structure for the age and gender groups. This was followed by MANOVAs of means of behavior problem scales broken down by age, gender, and family structure. Many of the symptoms associated with serious psychological disorders, such as sadness, disobedience, and anxiety, are also common among children who do not have a psychological disturbance. When these symptoms are observed episodically or every once in a while, they are not viewed as a cause for alarm about psychological maladjustment in the child. However, they are alarming when they occur continuously or chronically in a child. Because our interest in the adjustment of African American children includes both normally occurring symptomatology and serious disturbances, we separated reports of chronic problems (i.e., rated as often) and analyzed their prevalence by gender and age (see Table 2). Inspection of the frequencies of problems reported by parents of African American children reveal that difficulties most often occur in domains related to restlessness, agitation, and anxiety. About 1 in 6 African American children was described as often unable to sit still and 1 in 10 children was described as unable to concentrate. Being high-strung and fearful also occurred with great frequency.

Table 3 presents the frequencies of problems that combine the "often" and "sometimes" ratings. When reports of symptoms were examined for the effects of gender, boys were consistently more likely to be described as misbehaving, acting without thinking, being cruel and mean, and breaking 
TABLE 2

Percentage Population Exhibiting Behavior Problems Frequently, by Gender and Age Group

\begin{tabular}{|c|c|c|c|c|c|}
\hline \multirow[b]{2}{*}{ Behavior } & \multicolumn{2}{|c|}{ Children } & \multicolumn{2}{|c|}{ Adolescents } & \multirow[b]{2}{*}{ Total } \\
\hline & Male & Female & Male & Female & \\
\hline Can't sit still & 17.3 & 13.9 & 12.5 & 4.8 & 15.3 \\
\hline Argues too much & 13.2 & 13.6 & 14.9 & 16.1 & 13.4 \\
\hline Can't concentrate & 12.4 & 8.7 & 10.1 & 4.2 & 10.6 \\
\hline Fearful or anxious & 8.9 & 6.5 & 7.4 & 5.3 & 7.8 \\
\hline Very strong temper & 10.7 & 4.6 & 7.6 & 7.1 & 7.8 \\
\hline High-strung & 8.0 & 6.2 & 10.1 & 9.2 & 7.2 \\
\hline Cheats or tells lies & 7.8 & 5.0 & 3.0 & 4.5 & 6.4 \\
\hline Changes in mood & 7.2 & 5.0 & 3.0 & 4.5 & 6.1 \\
\hline Stubborn/sullen/irritable & 7.2 & 5.0 & 5.8 & 5.9 & 6.1 \\
\hline Misbehaving & 6.9 & 3.4 & 4.6 & 3.6 & 5.2 \\
\hline One-track mind & 3.7 & 4.0 & 4.3 & 2.4 & 3.7 \\
\hline Easily confused & 3.5 & 4.0 & 4.3 & 2.4 & 3.7 \\
\hline Acts without thinking & 4.3 & 2.5 & 4.9 & 3.3 & 3.4 \\
\hline Complains about love & 3.7 & 1.9 & 2.1 & 4.5 & 2.8 \\
\hline Disobedient at home & 3.2 & 2.2 & 2.7 & 2.4 & 2.7 \\
\hline $\begin{array}{l}\text { Trouble getting along } \\
\text { with other children }\end{array}$ & 2.6 & 1.2 & .9 & 1.2 & 2.1 \\
\hline Bullies, cruel, or mean & 3.4 & .3 & 2.1 & 1.2 & 1.9 \\
\hline Disobedient at school & 2.6 & .0 & 3.1 & 2.1 & 1.3 \\
\hline Trouble with teachers & 2.3 & .3 & 1.5 & 1.5 & 1.3 \\
\hline Not liked by others & 1.4 & .9 & 1.2 & .6 & 1.2 \\
\hline Feels worthless & 1.4 & .9 & 1.2 & .6 & .9 \\
\hline Unhappy, sad, or depressed & .9 & .3 & .9 & 1.2 & .6 \\
\hline Withdrawn & .9 & .3 & 1.9 & 1.5 & .6 \\
\hline Demands attention & 15.5 & 12.5 & & & \\
\hline Clings to adults & 6.9 & 9.4 & & & \\
\hline Cries a lot & 4.5 & 2.8 & & & \\
\hline Breaks things & 2.1 & 2.8 & & & \\
\hline Dependent & 1.2 & 1.5 & & & \\
\hline Secretive & & & 9.6 & 6.7 & \\
\hline Worries too much & & & 4.6 & 2.7 & \\
\hline Hangs out with troublemakers & & & 2.5 & 1.8 & \\
\hline Fears others out to get him/her & & & 1.2 & 1.5 & \\
\hline
\end{tabular}

things. Young boys were reported to cheat or tell lies significantly more often than young girls, $\left(\chi^{2}[1]=15.9, p \leq .001\right)$. Among the low frequency problems, young African American males were more likely than young females to act without thinking $\left(\chi^{2}[1]=10.1, p \leq .001\right)$, have difficulty concentrating $\left(\chi^{2}[1]=\right.$ $4.1, p \leq .05)$, have a strong temper $\left(\chi^{2}[1]=9.39, p \leq .005\right)$, be disobedient at 
TABLE 3

Percentage Population Exhibiting Behavior Problems Sometimes or Often, by Gender and Age Group

\begin{tabular}{|c|c|c|c|c|c|}
\hline \multirow[b]{2}{*}{ Behavior } & \multicolumn{2}{|c|}{ Children } & \multicolumn{2}{|c|}{ Adolescents } & \multirow[b]{2}{*}{ Total } \\
\hline & Male & Female & Male & Female & \\
\hline Changes in mood & 42.5 & 48.2 & 42.8 & 49.0 & 45.6 \\
\hline Argues too much & 43.0 & 44.1 & 46.3 & 44.0 & 44.4 \\
\hline Stubborn/sullen/irritable & 43.9 & 42.2 & 42.4 & 40.4 & 42.2 \\
\hline Fearful or anxious & 43.9 & 45.2 & $39.6 * *$ & 31.2 & 40.0 \\
\hline Can't sit still & 49.2 & 45.9 & $35.7^{*}$ & 28.3 & 39.8 \\
\hline Cheats or tells lies & $51.8^{* * * *}$ & 37.2 & 33.5 & 32.3 & 38.7 \\
\hline Acts without thinking & 41.7 & 30.4 & 37.3 & 32.4 & 35.5 \\
\hline Can't concentrate & $42.5^{*}$ & 35.1 & $37.3^{* * * *}$ & 22.9 & 34.5 \\
\hline Very strong temper & $39.3 * * *$ & 28.5 & 24.9 & 34.1 & 34.2 \\
\hline High-strung & 29.5 & 27.4 & 35.8 & 37.7 & 32.6 \\
\hline Disobedient at home & 34.9 & 28.5 & 25.3 & 22.6 & 27.8 \\
\hline Disobedient at school & $28.3^{* * * *}$ & 15.3 & $27.3^{* *}$ & 18.1 & 22.3 \\
\hline One-track mind & 23.4 & 20.5 & 25.3 & 19.0 & 22.1 \\
\hline Misbehaving & $27.7^{* * *}$ & 17.9 & 20.9 & 19.0 & 21.4 \\
\hline Complains about love & 18.6 & 17.6 & 16.8 & 21.4 & 18.6 \\
\hline Easily confused & 20.7 & 17.3 & 17.4 & 13.9 & 17.3 \\
\hline \multicolumn{6}{|l|}{ Unhappy, sad, or } \\
\hline depressed & 14.5 & 14.2 & $14.7^{*}$ & 20.8 & 16.1 \\
\hline Bullies, cruel, or mean & 15.3 & 11.7 & 13.1 & 9.2 & 12.3 \\
\hline Trouble with teachers & $11.1^{* * * *}$ & 3.9 & 18.2 & 13.0 & 11.6 \\
\hline Trouble with children & $15.3^{* * * *}$ & 11.5 & 8.3 & 9.8 & 11.2 \\
\hline Feels worthless & 10.0 & 6.1 & 13.6 & 11.6 & 10.3 \\
\hline Withdrawn & $8.9^{*}$ & 4.8 & 11.8 & 9.8 & 8.8 \\
\hline Not liked by others & 6.9 & 6.7 & 7.0 & 6.0 & 6.7 \\
\hline Demands attention & 45.9 & 49.7 & & & 47.8 \\
\hline Clings to adults & $34.0^{*}$ & 41.2 & & & 37.6 \\
\hline Dependent on others & 18.0 & 14.5 & & & 16.3 \\
\hline Cries a lot & 16.9 & 15.4 & & & 16.2 \\
\hline Breaks things & $11.8 * *$ & 6.0 & & & 8.1 \\
\hline Secretive & 38.9 & 37.6 & & & 38.3 \\
\hline Worries too much & 16.9 & 19.0 & & & 18.0 \\
\hline \multicolumn{6}{|l|}{ Hangs out with } \\
\hline troublemakers & & & 15.4 & 10.3 & 12.9 \\
\hline \multicolumn{6}{|l|}{ Fears others out to } \\
\hline get him/her & & & 8.9 & 6.3 & 7.6 \\
\hline
\end{tabular}

${ }^{*} p<.05 ;{ }^{* *} p<.01 ;{ }^{* * *} p<.005 ;{ }^{* * * *} p<.001$.

school $\left(\chi^{2}[1]=17.25, p \leq .001\right)$, and misbehave $\left(\chi^{2}[1]=10.03, p \leq .005\right)$. On the other hand, young females were more likely than younger males to cling 
to adults, $\left(\chi^{2}[1]=3.86, p \leq .05\right)$. Similarly, problem behaviors, such as breaks things, has trouble with teachers, feels worthless, is withdrawn, and is not liked by others, were reported with low frequency for children aged 4-11. However, the rates of these behaviors differed significantly for young boys and girls. Young boys were described as breaking things $\left(\chi^{2}[1]=3.86, p . \leq\right.$ $.01)$, being withdrawn $\left(\chi^{2}[1]=4.41, p \leq .05\right)$, and having trouble with teachers $\left(\chi^{2}[1]=13.16, p \leq .05\right)$ much more often than young girls.

Male adolescents were also more often described as having difficulty sitting still and concentrating, as disobedient at school, and as worried than were female adolescents.

\section{SCHOOL ADJUSTMENT}

Data on school adjustment were analyzed for the group as a whole and by age, gender, and family structure. On measures of suspensions, grade failure, student ranking, and academic performance, girls did significantly better than boys, young children performed better than older children, and children in multiple-adult households did better than those in single-adult biological mother households. A smaller proportion of young children (2.1\%) than adolescents $(22.4 \%)$ were suspended, $\chi^{2}(1)=109.8, p<.001$. Similarly, a smaller proportion of females $(10.9 \%)$ than males $(15.1 \%)$ were suspended $\chi^{2}(1)=4.73, p<.05$. Children living with both biological parents were suspended less often than were either children from single-mother $(12.6 \%)$ or other two-parent family structures $(17 \%), \chi^{2}(4)=9.3, p<.05$. With respect to repeating grades, young children fared better than adolescents $(16.2 \% \mathrm{vs}$. $23.1 \%), \chi^{2}(1)=8.99, p<.002$. Females fared better than males $(14.5 \%$ vs. $25.2 \%), \chi^{2}(1)=22.3, p<.001$. Figures 1 and 2 offer representations of these findings by family structure, age, and gender.

\section{MANOVA ANALYSES}

Each of the behavior problem subscales developed by Zill (1985) were treated as dependent variables in a two-way MANOVA using family structure and gender as the independent variables. Because of the differences in scale composition for young children and adolescents, MANOVAs are computed separately for children aged 4-11 and adolescents aged 12-17. Table 4 presents the means, standard deviations, and univariate and multivariate $F$ values for behavior problems by gender and family structure type. Main effects of family structure on behavior problems were most often observed for young children. 


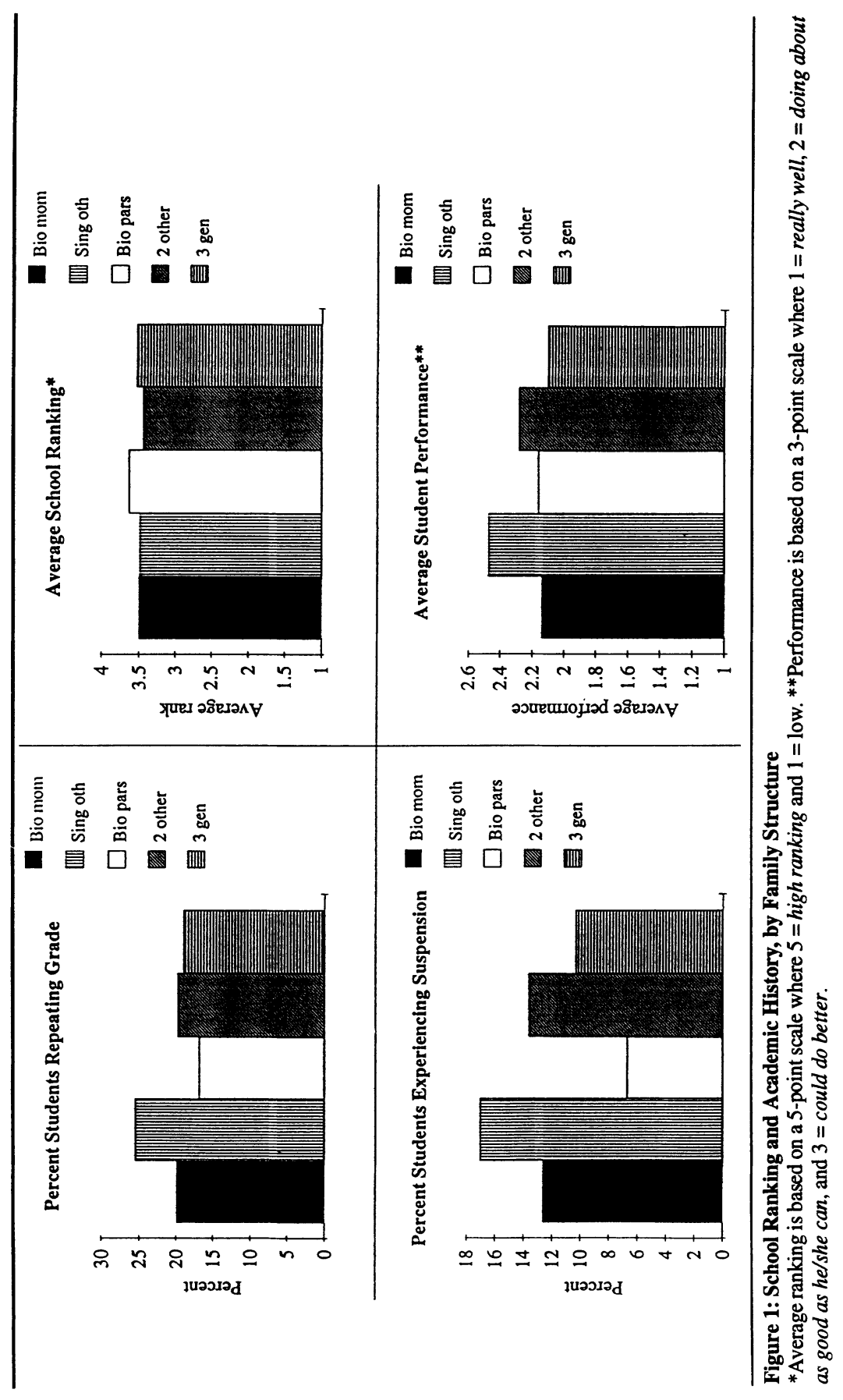




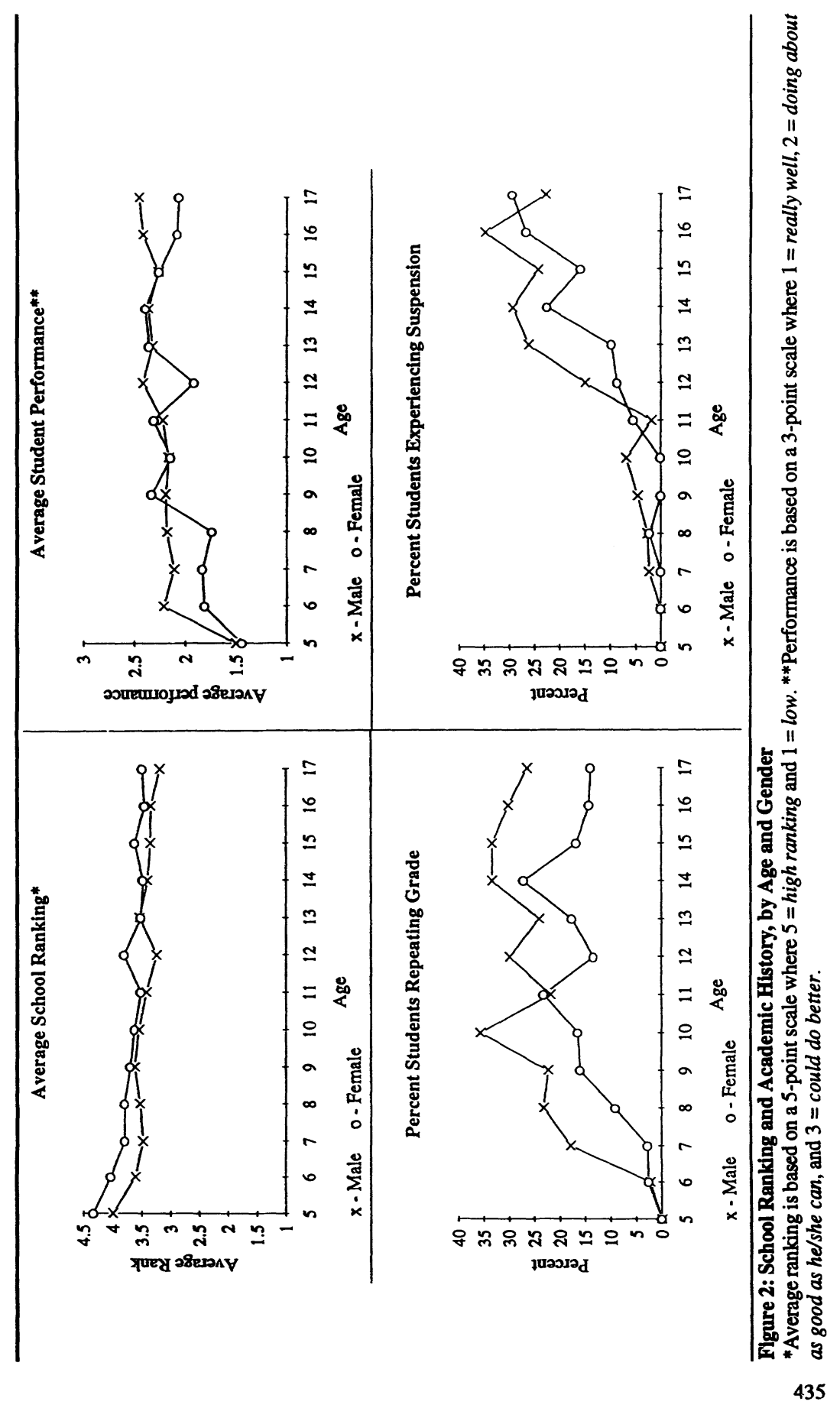




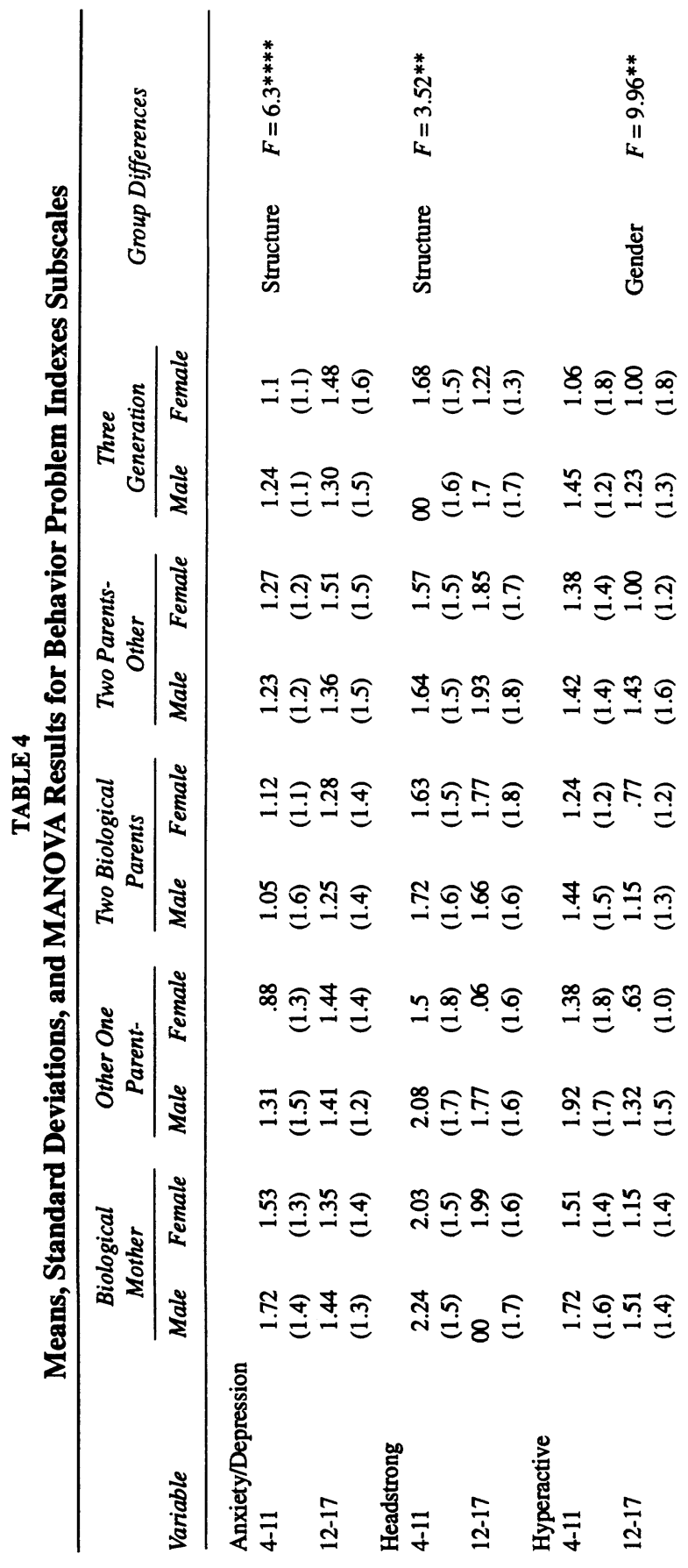




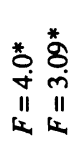
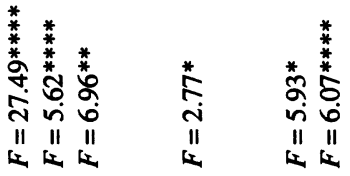

总总

壱总

曾

总总

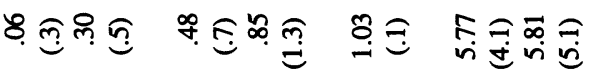

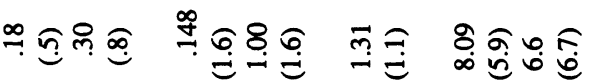

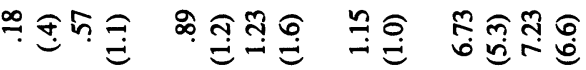

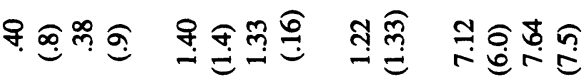

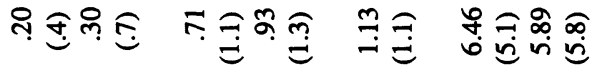

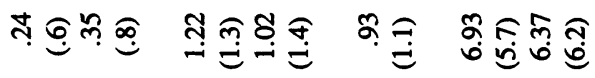

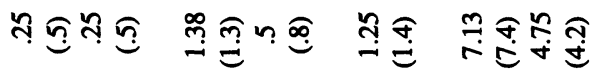

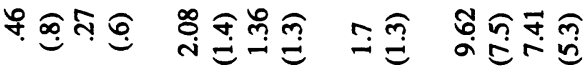

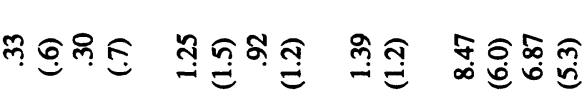

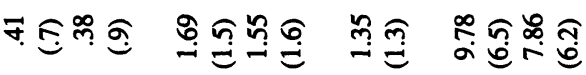

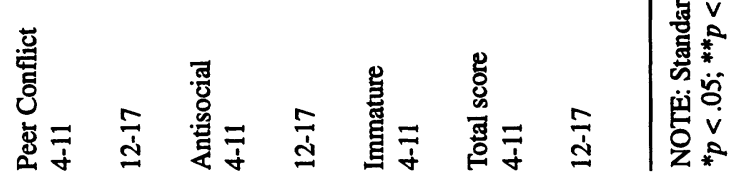


Significant differences were found for family structures on symptoms related to anxiety/depression $(F[4,676]=6.3, p<.001)$, being headstrong $(F[4,676]=3.52, p<.01)$, peer conflict $(F[4,676]=3.09, p<.05)$, antisocial behavior $(F[4,676]=5.62, p<.001)$, immaturity $(F[4,661]=2.77, p<.01)$ and for the total problem score $(F[4,667]=6.07, p<.001)$. On each of these variables, young children residing with a single-parent biological motheralone were rated significantly higher on the symptoms of behavioral and affective disorders than were young children in other family structures. Moreover, significant gender differences were observed for young children on some domains of behavior and affective problems. Young males were higher than young females in peer conflict (male mean $=.31$ vs. female mean $=$ $.23 ; t=1.88, p<.06$ ), antisocial behavior (male mean $=1.44 \mathrm{vs.} \mathrm{female} \mathrm{mean}=$ $.91 ; t=5.58, p<.000$ ), hyperactivity (male mean $=1.5$ vs. female mean $=$ $1.3 ; t=2.04, p>.05$ ), and on the total problem index (male mean $=8.03 \mathrm{vs}$. female mean $=6.98 ; t=2.49, p \leq .02$ ). Family structure did not have a significant effect on the ratings of behavior problems in adolescents. However, adolescent males were significantly higher than adolescent females on ratings of hyperactivity (male mean $=1.28 \mathrm{vs}$. female mean $=.93 ; t=3.43$, $p<.001$ ).

Post hoc comparisons also revealed that younger children from biological mother-only households exhibited a greater number of antisocial behaviors $(t=2.48, p<.01)$, behaviors related to peer conflict $(t=2.91$, $p<.01)$, and total number of behavior problems $(t=2.66, p<.01)$ than did children from three-generation households (see Table 4). All children residing in single-adult households exhibited a greater number of antisocial $(t=3.5, p<.001)$ and peer conflict behaviors $(t=2.14, p<.05)$ than did children living in households with two or more adults present. Children residing in one-adult households also had higher total behavior problem scores $(t=2.64, p<.01)$ than did children in multiple-adult households.

To summarize and present the effects of family structure on adjustment, graphs were produced showing the means scores by family structure. Figures $3 a$ and $3 b$ present the total Behavior Problem Index score by family structure for young children and adolescents, respectively. As explained in results of the MANOVA analysis, Figure 3a reveals marked discrepancies between family structures with a single adult (i.e., either biological mother alone or some other single adult) and those with multiple adults. The graphs show that children in single-adult structures are rated has having more problems than those living in multiple-adult households. In contrast, differences among adolescents are not pronounced. 


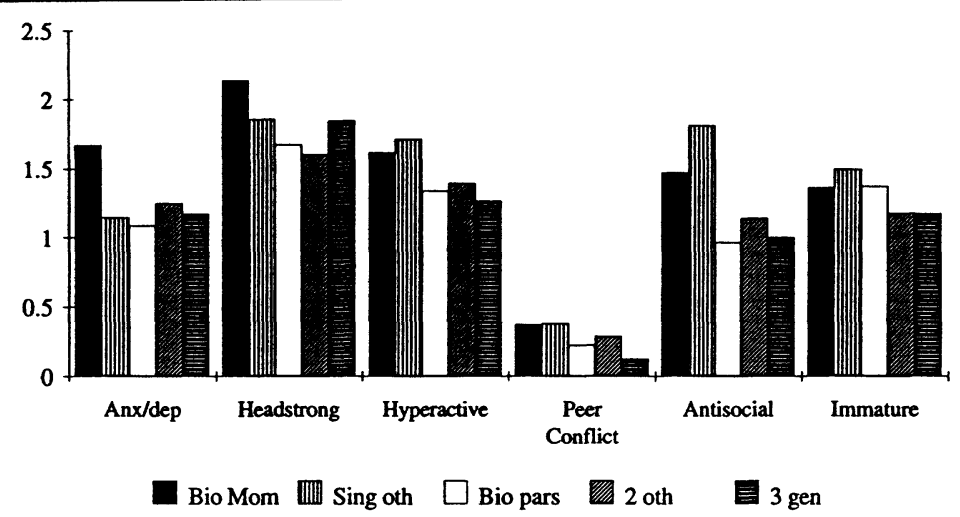

Figure 3a: Behavior Problem Index Scores by Family Structure-Age 4-11

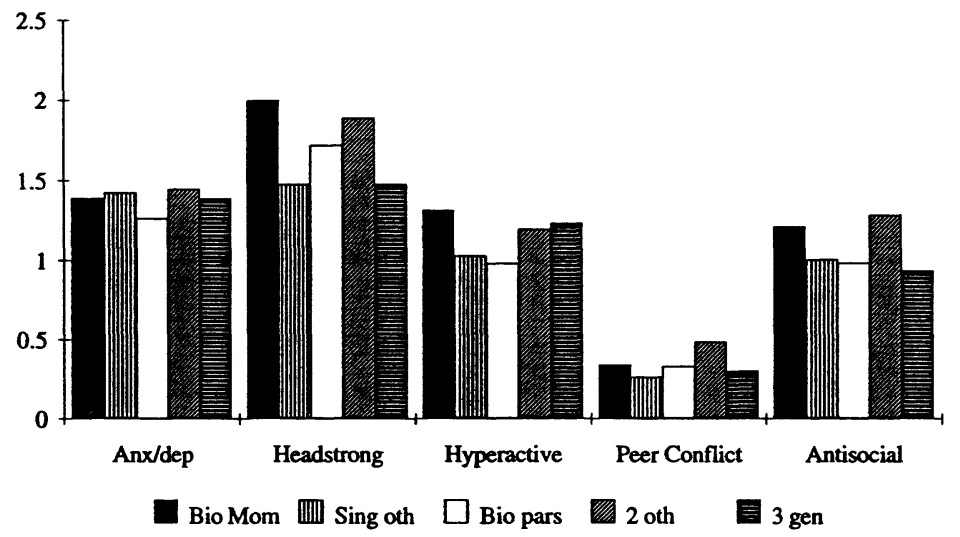

Figure 3b: Behavior Problem Index Scores by Family Structure-Age 12-17

Figures $4 \mathrm{a}$ and $4 \mathrm{~b}$ present the scales scores broken down by family structure. For young children, marked differences by family structure obtain for anxiety/depression, headstrong, peer conflict, antisocial, and immaturity. For adolescents, the effects of family structure are negligible.

Figure 5 presents a line graph showing the mean scores for the five subscales and the total Problem Behavior Index for each age from 4 to 17 separately for males and females. The graphs of total score and the peer conflict subscale show that boys generally score higher. Boys also score higher than girls on the anxiety/depression subscale with the exception of 


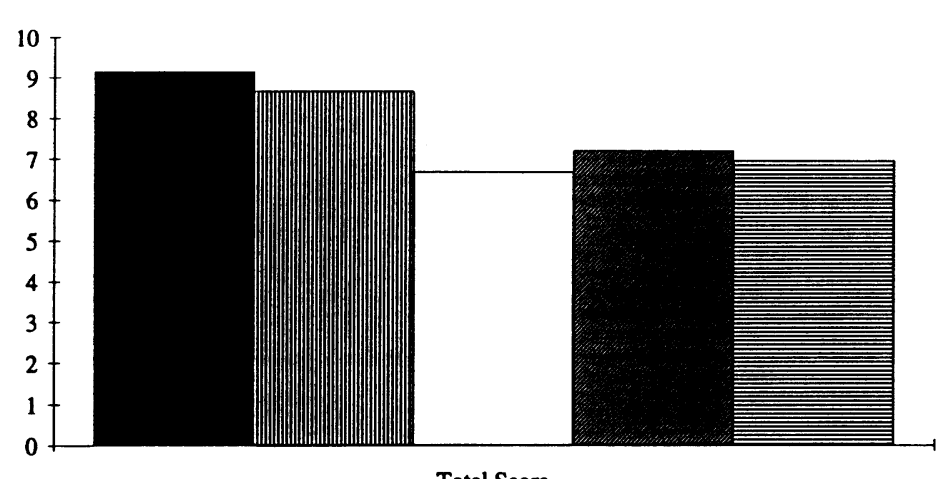

Total Score

Bio Mom 喘 Sing oth $\square$ Bio pars 2 oth 3 gen

Figure 4a: Behavior Problem Index Total Score-Age 4-11

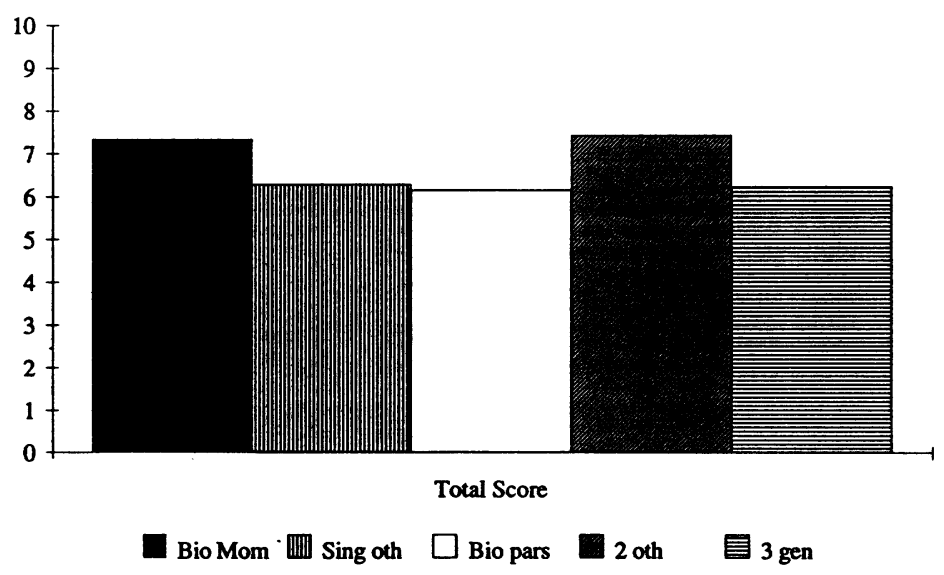

Figure 4b: Behavior Problem Index Total Score-Age 12-17

three ages: 6, 9, and 14 years. Across the age span from 4 to 7 years and at age 15 , boys are more headstrong. Inconsistent with most views of the preponderance of antisocial behavior among adolescent boys, the biggest discrepancies between ratings of boys and girls occur up to about age 13 . Between the ages of 13 and 14 girls' ratings of antisocial behavior climb precipitously. Thereafter, antisocial behaviors begin a downward trend to age 17. These differences are particularly striking among 15-year-olds. 


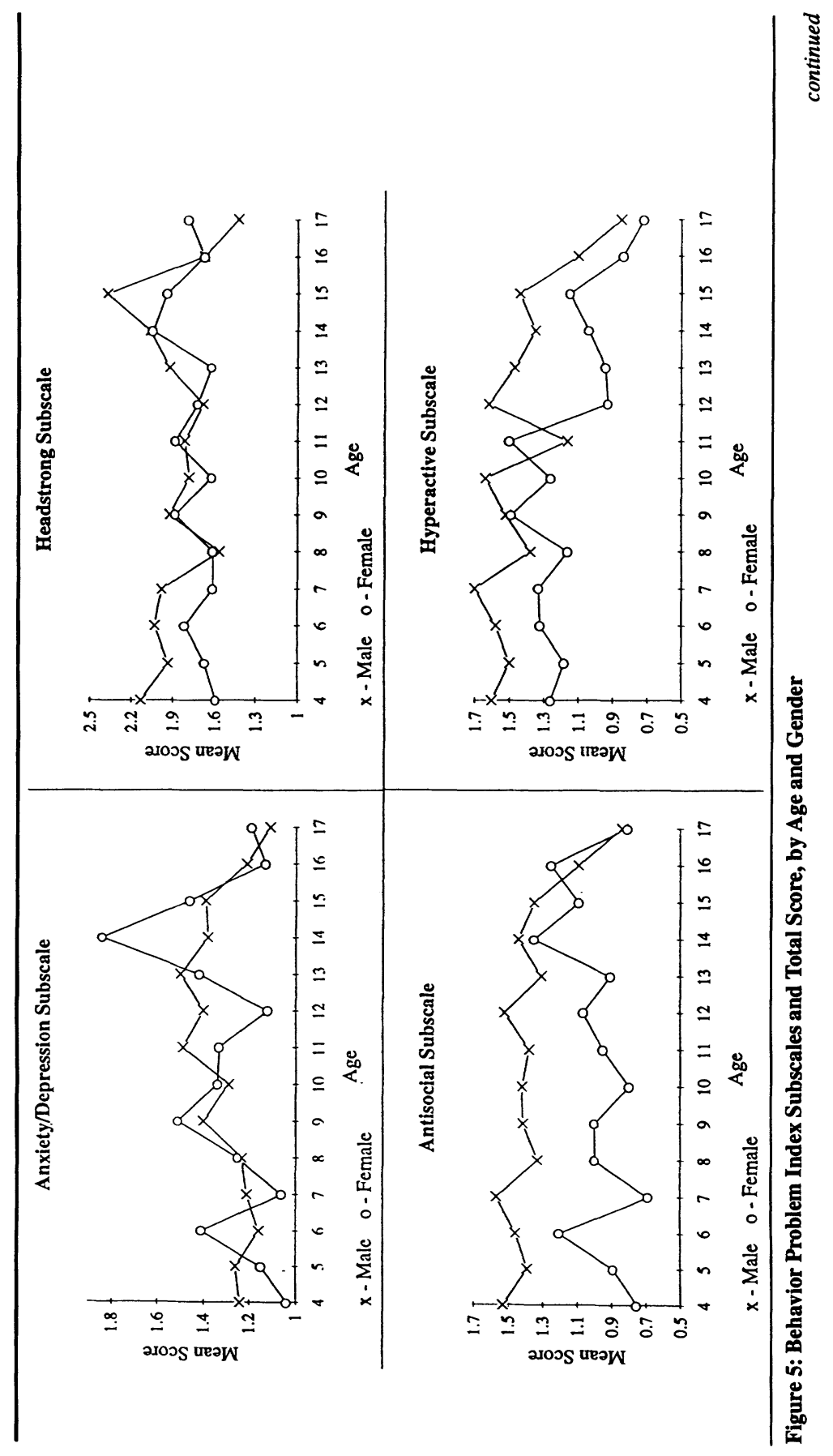




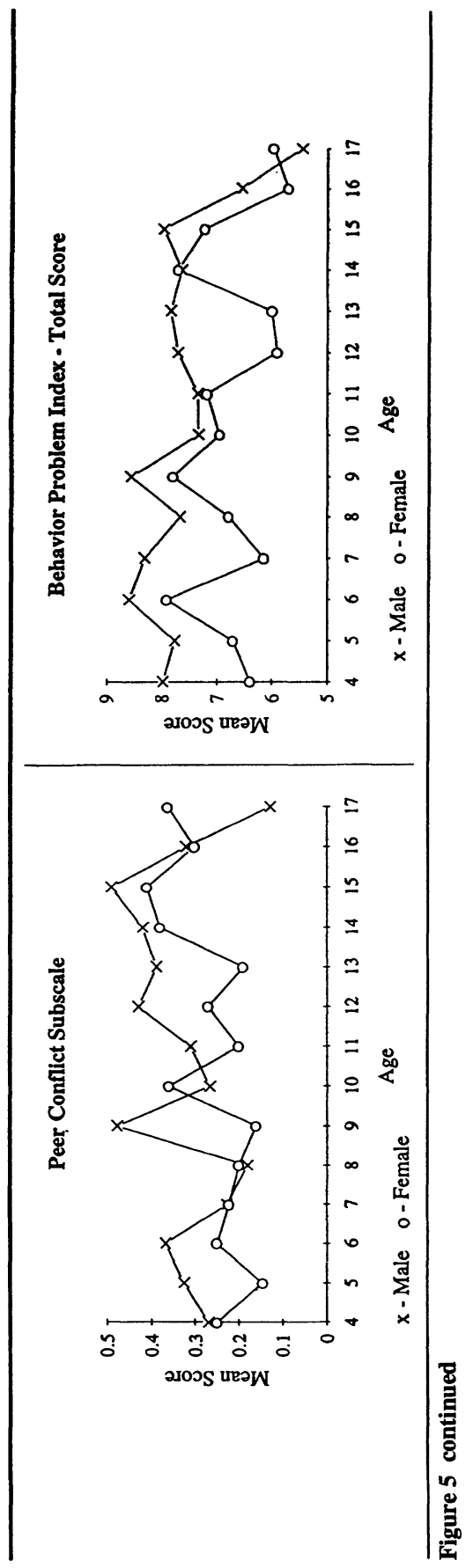




\section{DISCUSSION}

One of the most interesting aspects of the data is the extraordinary view they provide of how African American parents appraise their offspring. African American children and adolescents frequently are described by parents as restive and worried. In addition, almost half of this representative sample of African American children are described by their parents as moody at least some of the time. Problems of school performance are also significant, as indicated by parental reports of more than one child in five failing in school.

Differences in the evaluations of the behavior of boys and girls are unmistakable. Males more frequently than females are described by their primary caregivers as having behavior and affective disorders. Although it has been noted that older girls as a group tend to have more depression than adolescent boys, this difference does not occur in other domains of psychosocial functioning. Boys, particularly young boys, more often emerge as troubled, symptomatic, and psychologically vulnerable than girls. When asked to indicate existing problems, parents described young African American males as often hyperactive and agitated, unable to sit still, concentrate, control temper, and avoid arguments. If one were to designate children who are at risk, the data clearly point to young African American males. In this nationally representative sample, younger children, particularly younger boys, are most often rated as having difficulty with respect to behavior and affective disorders.

The age and gender patterns reported here are quite similar to those reported in many well-designed epidemiological studies conducted internationally. In most respects, the types and frequencies of problems reported by African American parents are remarkably similar to those reported by parents in England, New Zealand, Canada, and the United States as a whole (e.g., see Campbell, 1989). As a group, they exhibit a range of mood disturbances that taken together present a picture of a high level of agitation. Problems of concentration, restlessness, and noncompliance are legion, particularly among males. Thus the findings on young boys do not set young African American males apart from other young boys. What seems to distinguish African American males from other groups of children is that the prevalence rates of symptoms related to agitation appear to remain high even among adolescents. Summaries of the data from other studies suggest that the prevalence of symptoms of agitation, such as anxiety, hyperactivity, and concentration problems, decline with age; however, the prevalence rates of these symptoms among African Americans appear to persist unabated throughout adolescence.

These symptoms of agitation could be the thread of continuity tying together disturbances of mood and academic underachievement. Difficulties 
described as hyperactivity and inability to concentrate might be attributable to an anxiety response indicative of worry and concern about personal safety or peril to loved ones. The coincidence of these problems seem to arise from more than chance. Perhaps anxiety, hyperactivity, fighting, and poor school performance flow from a common source-environmental stress. Much of the arguing and fighting attributed to children, particularly boys, could have an anxiety base. In clinical work with African American children, it has been observed that they often reflect ambivalence about fighting. On one hand, they acknowledge that fighting will not make them feel better but that settling down, acting maturely (e.g., like a little man), and concentrating on their school work might. On the other hand, fights often arise because they sense danger or the possibility of injury from others. Although fighting is neither effective in the long run nor socially approved, it is seen as imperative for survival. In fact, a continual state of anxiety and agitation resulting from living in chronically stressful and unpredictable environments might impair the ability to make decisions based on accurate discrimination of real from imagined peril. Under stress, children find it difficult to judge quickly who will harm them and who will not. The stress is associated with a heightened vigilance regarding the possibility of danger, which is reflected in a chronic state of agitation, hyperactivity, and overreaction to provocation from others. In classroom settings, this agitation and hyper response to stimuli could be easily misconstrued as symptoms of attention deficit disorder with hyperactivity - inability to concentrate, impulsivity, distractibility, and noncompliance. The behavioral symptomatology of hyperactivity and poor social competence reported by parents might in fact be disguised symptoms of anxiety, which are the consequences of environmental stress, that are misdiagnosed. These symptoms, no matter the origin, contribute undeniably to problems of academic adjustment.

This research is consistent with other studies (e.g., Dawson, 1991) in demonstrating that children living in single-parent families do very poorly on behavioral adjustment. Some have called female-headed households "deviant" forms and suggested that they are incapable of providing suitable socialization experiences, particularly for young boys (Moynihan, 1968). Although the measure of family structure here is more precisely defined than in most studies of behavior in children (Achenbach \& Edlebrook, 1981; Achenbach, Howell, Quay, \& Conners, 1991; Dawson, 1991), these findings must be interpreted with caution. All but the two-biological-parent family structures are confounded by marital structure. Divorce, separation, and death are very stressful and traumatic experiences that can affect a child's behavior and a parent's perception of these behaviors. Moreover, single 
parents are often burdened by the stress of parenting alone, having little free time for self-maintenance, and stigma related to their status. These stressors may also affect a caretaker's reporting of behavior. The more time a caretaker spends with a child, the more aware or sensitive that caretaker might be of the behaviors of concern here.

To the extent that family structure influences socioemotional adjustment, this effect appears to be limited to young children. Children who live with their biological mother only have poorer adjustment scores than do children living with both biological parents. Family structure does not make a difference for adolescents.

Relatedly, the risk-reducing effect of living in a multiple-adult household does not occur for two-nonbiological-parent households. For the most part, these households were step-, foster, and adoptive families. It appears then that with respect to behavior problems, having a stepfather has similar effects as having no father in the house at all. It is possible that this finding is not related to the family structure but to the circumstances leading up to that family structure. Children living with stepparents have experienced divorce, death, or possibly abandonment by a biological parent. Living in adopted or foster families involves a unique set of extenuating circumstances that lead to their development and that are often linked to behavioral outcomes.

Although the above argument can clearly be drawn from results specific to the younger populations, the lack of a significant effect of family structure on adolescent adjustment raises questions about the continuing primacy of family life in the social development of adolescents. Adolescents are more self-sufficient, have higher stages of moral development, and spend more time away from home at school or with their peers. Thus they are able to obtain support or assistance outside the household, reducing the burden on their caretaker. Older children are more likely to understand events such as divorce and death and therefore be less likely to place blame or to act out in anger. Similarly, adolescents might understand the value of truth and consistency in behaviors more so than their younger counterparts. Each of these developmental stage-related phenomena interact with caretaking and can result in different types of behaviors. These results suggest that peer influence might become a more critical determinant of behavior at this later stage of development.

Although these effects remain a puzzle and elude a single convincing explanation, diverse factors are offered to account for the patterns obtained, including gender differences in socialization, hormones, culture, poverty, family structure, and the absence of suitable male role models in socializing institutions such as the family, day care, schools, and neighborhoods. The 
data suggest that some aspects of the social and cultural environment-for example, family structure and its correlates and its precursors-might in fact be related to rates of disorders. Overall, the findings of this study offer insight into the prevalence of behavior problems in a nationally representative data set. More research must be done, however, to understand the stresses and strains that African American children and their caretakers experience. This should ultimately lead to a clearer indication of what optimal living environments and life opportunities should be.

\section{REFERENCES}

Achenbach, T. M., \& Edlebrook, C. (1981). Behavioral problems and competencies reported by parents of normal and disturbed children aged four to sixteen. Monographs of the Society for Research on Child Development, 46(1, Serial No. 188).

Achenbach, T.M., \& Edelbrock, C. (1983). Manualfor the Child Behavior Checklist and Revised Child Behavior Profile. Burlington, VT: Queen City Printers.

Achenbach, T. M., Howell, C. T., Quay, H. C., \& Conners, C. K. (1991). National Survey of Problems and Competencies among Four- to Sixteen-Year-Olds. Monographs of the Society for Research on Child Development, 56(3, Serial No. 225).

Campbell, S. B. (1989). Developmental perspectives. In T. H. Ollendick \& M. Hersen (Eds.), Handbook of child psychopathology (2nd ed.). New York: Plenum.

Costello, E. J. (1989). Developments in child psychiatric epidemiology. Journal of the American Academy of Child and Adolescent Psychiatry, 38, 836-841.

Dawson, D. A. (1991). Family structure and children's health and well-being: Data from the 1988 National Health Interview Survey on Child Health. Journal of Marriage and the Family, 53, 573-584.

Maccoby, E. (1980). Social development: Psychological growth and the parent-child relationship. New York: Harcourt Brace Jovanovich.

Masten, A. (1989). Resilience in development: Implications of the study of successful adaptation for developmental psychopathology. In D. Cicchetti (Ed.), The emergence of a discipline: Rochester symposium on developmental psychopathology (pp. 261-294). Hillsdale, NJ: Lawrence Erlbaum.

Moynihan, D. P. (1968). The Negro family: The case for action. Washington, DC: Office of Planning and Research, U. S. Department of Labor.

Offord, D. R., Boyle, M. H., \& Racine, Y. (1989). Ontario child health study: Correlates of disorder. Journal of the American Academy of Child and Adolescent Psychiatry, 28, 856-860.

Ogbu, J. (1988). Cultural diversity and human development. In D. Slaughter (Ed.), Black children and poverty: A developmental perspective. San Francisco: Jossey-Bass.

Peterson J. L., \& Zill, N. (1986). Marital disruption, parent child relationships, and behavior problems in children. Journal of Marriage and the Family, 48, 295-307.

Willis, D. J., \& Walker, E. (1989). Etiology. In T. H. Ollendick \& M. Hersen (Eds.), Handbook of child psychopathology (2nd ed.). New York: Plenum.

Zill, N. (1985). Behavior problem, scales developed from the 1981 Child Health Supplement to the National Health Interview Survey. Washington, DC: Child Trends, Inc. 